\title{
Developing Better Teacher Evaluation
}

\author{
Peace Ebele Ilechukwu Chukwubikem
}

Bluebell International School,

Port Harcourt, Rivers State, Nigeria

\section{Doi:10.5901/jesr.2013.v3n6p49}

\begin{abstract}
Teacher performance appraisal is the process of arriving at judgment about individual teacher's performance against the background of his work environment and his future potential for the school system. Increasing teacher and teaching effectiveness is arguably the paramount challenge facing public primary and secondary education in Nigeria. It is universally acknowledged that improvement in educational systems is crucially dependent on effective teacher self-evaluation. Effective teaching evaluation is a key to helping teachers improve their teaching, which then improves student learning. Teacher evaluations are often design to serve two purposes: to measure teacher competence and to foster professional development and growth. Effective teacher appraisal can also help schools to become sensitive to individual talent, performance and motivation by allowing teachers to progress in their career and take on new roles and responsibilities based on evaluations of their performance. Experienced teachers often state that the evaluations are not productive. Some of this dissatisfaction is based on experience which can be avoided. Teachers do not have any inputs: they are not involved in the evaluation criteria. Criteria for evaluation are determined by school boards who usually decide how the criteria are tailored. This leads teachers to distrust the evaluation process and question the validity of the results it produces. To be more effective, teachers need to participate actively in the evaluation process. Evaluators should spend time to make sure quality information is gathered.
\end{abstract}

\section{Introduction}

Teacher performance appraisal is the process of arriving at judgment about individual teacher's performance against the background of his work environment and his future potential for the school system. It is the overall assessment of staff normally covering the period of one year or more. The main focus of the appraisal is on the job evaluation. Performance appraisal covers all information regarding the performance of the individual job.

It is universally acknowledged that improvement in educational systems is crucially dependent on effective teacher self-evaluation. Indeed, teachers instinctively wish to reflect on their work, evaluate it and look for ways to improve it. However, effective self-evaluation is not simply a process for the individual, but involves colleagues in a variety of ways. A fundamental principle is that teachers should also see themselves as learners.

\section{Problem}

Increasing teacher and teaching effectiveness is arguably the paramount challenge facing public primary and secondary education in Nigeria. The evidence suggests that most teachers' professional development has little if any impact. Most times teachers attend professional workshops with no difference in the quality of their lesson delivery. The gaps between the stated aims of Federal policy, the needs of the teacher workforce, and proven solutions that improve teacher and teaching effectiveness are a serious impediment to any effort to improve student 
achievement. Schools all across all over the world are busy developing and implementing teacher evaluation system. A good teacher evaluation should be able to discriminate between effective and ineffective teacher, to measure teacher quality and aid in developing highly skilled teacher workforce

Effort should be made more quickly in designing and implementing more effective teacher evaluation system. Teacher evaluation systems that are designed to help teachers improve have their primary characteristics: the system should be comprehensive and specific. Comprehensive means the model includes all those elements that researchers has identified as associated with student achievements. Specific means model identifies classroom strategies and behaviors at a granular level. In America there is rigorous training for teachers not just before one can become a teacher, but throughout their entire career. Good teacher development and ongoing development while you are a teacher is one of the key components in making our education system successful. Making sure that teachers are well prepared is very important.

\section{Thoery of Motivation}

Various individuals come to an organization with diverse needs and expectations which they expect to accomplish in exchange for their services to the organization. These needs and expectations could be defined in terms of the rewards the workers expect to get after exhibiting a particular behaviour. According to Flippo $(1980 ; 342)$ just as the employee has certain needs that the organization is expected to supply, the organization has certain type of behaviour that it wishes elicit from employees.

In 1960, theory $X$ and $Y$ was postulated by McGregor which he related to the physiological needs of the people with regards to their particular jobs and various forms of management. Theory $X$ assumed that subordinates in any organization is naturally lazy and avoids work where necessary. Incentives are therefore needed either in form of monetary, sanctions like loss of job, demotion, praise and so on. Theory $Y$ assumes that people will willingly accept responsibility if they are given the right environment in terms of work conditions and attitude.

Rivers state government is investing heavily in the education sector especially primary and secondary schools. The school buildings are estethetically beautiful, far better than that of most private schools, well furnished and airy classrooms, state of the art ICT laboratories, with spacious a beautiful playgrounds yet majority of the parents do not want to have anything to do with them and. Teachers have continued to display nonchalant attitude to work which has contributed to students poor outings in external examinations. Okeke (2004) summarized teacher's performance in secondary school to include

1. Commitment to the students and students learning

2. Commitment to the parents

3. Commitment to the community leadership and community

4. Commitment to the employer

5. Commitment to the professional knowledge, teaching practice-ongoing professional learning

There is an urgent need to restore people's confidence in public school. One way to improve the system is through effective evaluation. Bronwyn (2001) in Ajie (2005) suggested that one of the objectives of performance assessment is to provide financial incentives for teachers to increase their effort it is important to ensure that an effective evaluation system is developed to motivate teacher to work hard in attempts to ensure that the aims and objectives of education are achieved. According to Cole (1982.382) the objectives of formal system of appraisal are

a. To identify current level of job performance

b. To identify employee strength and weakness

c. To enable employees to improve on current performance

d. To identify training and development needs 
e. To identify potential performance

f. To provide the basis for salary reviews.

g. To encourage and motivate employees.

\section{Effective Evaluation}

A teacher's primary goal is to facilitate student learning. Effective teaching evaluation is a key to helping teachers improve their teaching, which then improves student learning. Measuring teacher competence and simultaneously encouraging development growth is the purpose of effective evaluation of teachers. Quality evaluation will help teachers develop their course and curriculum to best meet students need. Effective teacher evaluation provide teachers with regular feedback to help improve professionally, provide feedback to school to administrators to help them build strong educational systems, identify professional development needs and identify clear learning need expectorations. It is a resource tool to help understand how students learn while determining effective teaching strategies. Appraisal is necessary to maintain standards set by the ministry. There is a need to examine the performance of teachers in public school generally.

Nigerian education system needs reform in the area of teacher evaluation to encourage greater commitment. Developing effective way to evaluate school teachers holds the promise for improving the school education experience for the millions of students who will be taught by these teachers. A central part of education reform today is the wide-ranging and unprecedented effort to either revamp existing teacher evaluation system or develop and implement entirely new systems. In the past three years, some countries have made some change to their teacher evaluation

- Providing clear lesson objectives.

- Understanding students' background and comfort with the material.

- Using more than one delivery mechanism.

- Providing multiple examples.

- Providing appropriate number of examples (illustrations of the wrong way to do something).

- Maintaining an effective pace.

- Providing students with feedback about their learning.

- Engaging in timely use of guided practice.

- Explaining important concepts clearly.

- Keeping students actively engaged throughout a lesson.

Studies on the RATE system indicate that it discriminates between effective and ineffective teachers much better than some popular teacher evaluation models do (Strong, 2011). RATE's list is references to such commonly cited elements as the teacher-student relationship and classroom management. These elements are recognized effective teaching. For example, in their review of the research on 228 variables identified as having measurable relationships with student achievement, Wang, Haertel, and Walberg (1993) listed classroom management at the top. Classroom management has continued to be considered an important aspect of effective teaching (Good \& Brophy, 2003). Likewise, the teacher-student relationship is prominently positioned in the theory and research regarding student behaviour (Evertson \& Weinstein, 2006). Indeed, Sheets and Gay (1996) identified poor teacher-student relationships as the root cause of many, if not most, discipline issues.

Management and teacher-student relationships have research supporting their connections to important student outcomes. These elements are important correlates with student achievementup to a point. If a teacher has not achieved a certain level of competence in these areas, student achievement will suffer. In addition to the elements mentioned other elements are appearance, composure, attitude towards supervision, punctuality, regularity to assemblies, classroom effectiveness- classroom control, performance of students in internal and external examinations, 
interpersonal relationship, involvement in curricular activities, distinguished achievement, sense of responsibility excuse duty, use of period, classes missed, relationship with staff and students, public, participation in staff and PTA meetings, integrity respect to constituted authority, self discipline and manners, professional growth.

The 41 elements in appendix 1 represent the diversity of strategies that a comprehensive model of teacher evaluation should include. Rapid Assessment of Teacher Effectiveness (RATE) was designed with an explicit measurement purpose-to effectively and efficiently determine teacher competence in the classroom (Strong, 2011). The model includes only 10 categories of teacher behaviour that appear sufficient to rank teachers in terms of pedagogical skill. Those categories are

\section{Purpose of the Study}

Performance appraisal is a management tool that attempts to ensure that the aims and objectives of education are achieved. In spite of huge investment by the government on education critics believe that there is fall in quality of education in public schools which is evident in students' performance in external examinations such as WASCE, NECO, and J AMB.

It is observed that teachers are not performing their job satisfactory. However, education stakeholders are beginning to find some agreement in the idea that teacher appraisal can be a key lever for increasing the focus on teaching quality and continuous professional development for teachers, in keeping with the growing recognition that the quality of teaching affects student learning outcomes. Highly visible teacher appraisal also provides opportunities to assist recognize and reward teaching competence and high performance. This, in turn, may help address concerns about the attractiveness of teaching as a career choice and about the image and status of teachers, including teachers' feelings that their work is not sufficiently valued. Since formative appraisal can also help to raise teachers' self efficacy, it is a key component of effective teacher policies.

Effective teacher appraisal can also help schools to become sensitive to individual talent, performance and motivation by allowing teachers to progress in their career and take on new roles and responsibilities based on evaluations of their performance. As more and more parents demand quality education for their children, teacher appraisals provide a way for schools to be accountable for the quality of education in their classrooms and to address underperformance among teachers. There are large variations in approaches to teacher appraisal, ranging from highly sophisticated national systems to informal approaches left entirely to the discretion of individual schools (in the private school sector). Issues of teachers' working conditions, discipline and appraisal have been treated with levity. This attitude has affected the behaviour of teachers and their productivity generally. For any organizational system to achieve its purposes, adequate working condition and appraisal system must be formulated for the workers.

With dissatisfaction with the traditional approach to teacher performance appraisal and the need for educational reforms, it has now becomes imperative to reform and strengthen the evaluation system of teachers to encompass the new standards for teaching practice. The reason for this development is to enhance professional practice as a control for teachers' performance appraisal.

\section{Types of Evaluation}

Performance management refers to the formal teacher-appraisal processes designed to ensure that individual and organizational goals are met. This includes all types of appraisal related to managing and developing a teacher's career. As such, performance management is part of wider processes and systems for measuring, monitoring and enhancing the performance of teachers. It includes processes such as teacher registration, regular appraisals and appraisals for promotion.

Teacher registration, or certification, processes officially confirm teachers as competent for 
teaching. Advancement to fully registered teaching status typically occurs upon completion of a probationary period and/or following an appraisal against registration/certification criteria. The process typically involves external evaluators or a national agency responsible for teacher registration.

Regular appraisal is usually a process internal to the school, regulated by general labour-law provisions requiring teachers' employers to regularly evaluate their employees' performance. The process is generally connected to a discussion and plan regarding the teacher's working conditions, responsibilities, professional development, and

career and salary advancement.

Appraisal for promotion is a process that is separate from regular teacher appraisals in some countries. It is often voluntary and takes place in relation to decisions on employment status. Many countries do not have a specific process for this type of appraisal but integrate this function into regular teacher appraisals.

Reward schemes involve teacher appraisals that are explicitly designed to identify a selected number of high-performing teachers to acknowledge their teaching competence and performance through rewards or one-off salary increases.

\section{System of Appraisal in Nigerian Schools}

Governments everywhere in the world invest a lot of money on education for a purpose. They are therefore interested in the outcome of the system to ensure that the aims and objectives are achieved. Officials of ministries of education and school board go to schools from time to time to guide, help, advise and direct teachers and school heads in order to bring about an improvement in teaching and learning process. In Nigerian school system appraisal of teacher is undertaken by supervisors. A supervisor is a person formally designated by an organization to interact with members of the teaching staff in order to improve the quality of teaching and learning. Ogunsaju (1978) added that supervisors are mostly educational officers working with the ministry of Education charged with the following responsibilities.

In Nigeria there is no regular appraisal. Nigeria teachers' evaluation system is summative: to determine teachers grade levels and salary. This appraisal for promotion is a process that is separate from regular teacher appraisals in some countries. It takes place in relation to decisions on employment status. Many countries do not have a specific process for this type of appraisal but integrate this function into regular teacher appraisals. Teachers are supposed to be evaluated once in three years. However it is lamentable that in actual practice promotion interview is embarked on only when government is prepared to make money available to the upward review of salary. It is commonly referred to as Promotion interview promotion, It consists of oral and written tests. The written test tests teachers' knowledge of social, general and current affairs as well as practice and principles of education. Secondly the teachers' lesson notes are examined, appearance, and communication skill. Certificates are verified. Report of evaluation is never discussed

Pay has to be tied to performance. However, teachers are getting deferential pay now, and they are getting it for things that do not matter, like pure seniority and academic qualification which has resulted in teachers pursuing all sorts of part time academic programmes the most common being sandwich programme. Each performance appraisal must include at least one classroom observation. Post observation meeting to review the result.

\section{Purpose}

There are several reasons for the recent interest in enhanced teaching quality. These include: higher participation rates, increased costs of education, public demand for accountability, and a need to develop practical skills Teacher evaluation is the cornerstone of new performance based teacher compensation system. It should also be a way to improve teaching practice, a way to help 
teachers get better. The extent to which any of this can happen rests on evaluation that can consistently determine who are the more and less effective teachers in our classrooms. Information to accomplish this comes from two sources. First we can use teacher-related input to the education process such as classroom teaching observations or classroom artifacts such as: lesson plan and teacher-designed student assessment. From these measures promote student learning.

Second, we can measure outputs from teaching-learning process -actual student performance and based on these measures make inferences about the teacher's contribution to that output. In each case doing this well for school teachers is a challenge. One of the values of putting a meaningful teacher evaluation system in place is to help a teacher understand where they are when teaching similar kids. From these a teacher would know how he was doing if his failures were due to a student's background or due to things he has no control over. This is not all about performance pay or management- it's all about giving teachers real information about the jobs that they are doing. High-quality teacher evaluation systems are seen as one lever for improving the teacher workforce and hence the outcomes of students.

\section{Structure of Effective Teacher Evaluation}

Teacher evaluations are often design to serve two purposes: to measure teacher competence and to foster professional development and growth. There are two types of evaluation, formative and summative. Formative evaluation provides teachers with teaching skills; summative evaluation determines salary or dismissal. Using both of these tools enhances teachers' satisfaction and professional development. Teaching involves the teacher, student and the administrator. The structure of the evaluation should include

- Counsel with the administrator to achieve goals.

- These goals include clear communication with a teacher explaining how she will be evaluated.

- The standards of objectivity, along with the teacher's ability to relate to teaching skills and opportunities for carrier development, are the determining points in the effective evaluation.

- The teacher should be give opportunity to be observed in many different lessons to get a fully rounded view of the teacher's capability.

- Observation as well as review of her lesson plan should be including in the evaluation. Asking other professional to join in the evaluation process ensure a more balanced view. Using peer evaluation, a valuable learning tool for teachers to receive feedback by those who view her daily, adds to a more rounded evaluation.

- A teacher evaluation system should give teachers useful feedback on classroom needs, the opportunity to learn new teaching techniques, and counsel from principals and other teachers on how to make changes in their classrooms. To achieve these goals, evaluators must first set specific procedures and standards.

The standards should relate to important teaching skills, be as objective as possible, be clearly communicated to the teacher before the evaluation begins and be reviewed after the evaluation is over, and be linked to the teacher's professional development. Evaluators should consider a variety of teaching skills. If the evaluators use several sources of information about a teacher's performance, they can make a more accurate evaluation. Some procedures evaluators can use are to:

- Observe classroom activities. This is by far the most common form of data collection of evaluation. The goal of class observations is to obtain a representative sample of a teacher's performance in the classroom. Evaluators cannot accomplish this goal with a sample of only a few hours of observation or with an observation of only one class. Observations can be formal and planned or informal and unannounced. Both forms of evaluation can provide valuable information. 
- Review lesson plan and classroom records. Lesson plans can reflect how well a teacher has thought through instructional goals. Looking at classroom records, such as tests and assignment, can indicate how well a teacher has linked lesson plans, instruction, and testing.

- Expand the number of people involved in the evaluations. Most often principals and department supervisors conduct evaluations. Again, many state laws and collective bargaining agreements specify that teacher's supervisor evaluate their performance. This system works well if the only goal of evaluation is to determine competence. If the goal of the evaluation is to promote growth, however, other evaluators should participate. Selfevaluators give teachers' perspective on their work. Surprisingly, few school systems require self-evaluators. Peer and student evaluations, if schools administer them properly, can also benefit teachers.

Increase the awareness of parents and guardian of students concerning the effectiveness of teachers. For example, the Rapid Assessment of Teacher Effectiveness (RATE) was designed with an explicit measurement purpose-to effectively and efficiently determine teacher competence in the classroom (Strong, 2011)

- Providing clear lesson objectives.

- Understanding students' background and comfort with the material.

- Using more than one delivery mechanism.

- Providing multiple examples.

- Providing appropriate no examples (illustrations of the wrong way to do something).

- Maintaining an effective pace.

- Providing students with feedback about their learning.

- Engaging in timely use of guided practice.

- Explaining important concepts clearly.

- Keeping students actively engaged throughout a lesson

- Teachers who want to improve their teaching are eager to know how other teachers and their students view them. These are the people who interact with the teacher every day; their; their perspective should not be ignored during the evaluation process. Boyd (1989)

\section{Reporting the Results of the Evaluation}

A post-observation conference can give teachers feedback on their strengths and weaknesses. Evaluators must remember to deliver the feedback in a positive and considerate way; offer ideas and suggest changes that make sense to the teacher; maintain a level of formalities necessary to achieve the goals of the evaluation and maintain a balance between praise and criticism. Give enough feedback to the useful and not so much that the teacher is overwhelmed. Rapid Assessment of Teacher Effectiveness (RATE) was designed with an explicit measurement purposeto effectively and efficiently determine teacher competence in the classroom (Strong, 2011)

\section{Teachers' Concern in Reporting the Results}

An evaluation is a process that when handled well can give much needed information or criticism. Giving feedback in a positive, compassionate, professional delivery enables the teacher to use the evaluation as a growing process. Not overwhelming the teacher with information that is not useful is a priority. Experienced teachers often state that the evaluations are not productive. Some of this dissatisfaction is based on experience which can be avoided.

Teachers do not have any inputs are not involved in the evaluation criteria. Criteria for evaluation are determined by school boards who usually decide how the criteria are tailored. This leads teachers to distrust the evaluation process and question the validity of the results it produces. 
To be more effective, teachers need to participate actively in the evaluation process. Evaluators should spend time to make sure quality information is gathered.

- Teachers are concerned that evaluators are not trained well nor have no teaching experience.

- An effective evaluation is meaningful for the teachers and the school system, providing information and enhancing students' needs. Teachers' capabilities and school ineffectiveness.

- Evaluators do not spend enough time on the evaluation. They should make out time to gather quality information and provide quality information and useful feedback.

- Evaluator should have special training to help them plan and carry out successful evaluation.

- Result of evaluation should be used to further teacher development. The result should figure into salary increases, promotions or any meaningful programme for professional development.

Teachers are an obviously critical component of the quality of that preparation. In years teachers are being evaluated, they do a better job. Students scores go up compared to off years. A school teacher should have a very good idea of how well he is doing. Periodically throughout the year, he should give his students opportunities to conduct anonymous written evaluation of himself. This feedback can be used to inform teachers and make some adjustments. He should give informative and summative assessment throughout the year to gauge student learning, have informal discussions throughout the school with students before school, after school and in the school library during planning period. Teachers do not bother to improve themselves and be authority but just mark time. There is a dear need to encourage teachers to work towards being authority in the area of their specialization, not just an ordinary class teacher. If we want to know how the teacher is doing it will help to ask the students. Student can be asked what they do in class. A simple self-report inventory that asks the students to state what they did - did they take note, talk to a classmate, ask questions?

\section{Benefits}

Quality teaching begins with a teacher's formal education. The least educational qualification for one to teach in Nigerian schools is Nigerian Certificate in Education (NCE). However the teacher grows through a process of continuous improvement gained through experience, targeted professional development and the insights and direction provided through thoughtful, objective feedback about the teachers' effectiveness. Teacher evaluation can result to teacher growth which promotes school effectiveness (Duke et al (1986).

- Provide schools a transparent and consist teacher evaluation system that ensures effective teaching and promotes professional teaching.

- Provide feedback and a support system that will encourage teachers to improve their knowledge and instructional skills in order to improve student learning.

- Provide a basis for making teacher employment decision.

- Provide an integrated system that links evaluation procedure with curricular standards, professional development activities, targeted support and human capital decisions.

- Encourage highly effective teachers to undertake challenging assignment.

- Support teacher's roles in improving students' educational achievements.

Linking evaluation and development is a difficult task for teachers, evaluators, and principals. Although there are few easy answers, evaluation can be used to work with teachers to set specific, achievable goals; provide constructive criticism and suggestions to improve weak areas and amplify strengths enlist experienced teachers to help improve the performance of less experienced teachers 


\section{Steps in the Evaluation Process}

How often will a teacher be evaluated? 2 years twice a year. 3-5 years 2 times. Each performance appraisal must include at least one classroom observation. Post observation meeting to review the result. Each performance appraisal must include at least one classroom observation. Post observation meeting to review the result.

\section{References}

Ajie, C. A (2006) Teachers' performance appraisal in secondary schools in Rivers State. Unpublished PhD Dissertation, University of Port Harcourt.

Baridon (1999:127) Management and Organizational Theory. Port Harcourt Sherbrook associates.

Boyd, R.T.C (1989) Improving Teacher Educations. Practical Assessment, Research \& Evaluation. . http://pareonline. net/getvn.asp?v Retrieved from internet.

Brownyn (2001) in Ajie.C. A (2006) Teachers' performance appraisal in secondary schools in Rivers State Cole, G.A (1982). Management: Theory and Practices. Bereclose, Winchester D.P publication.

Danielson C (2011.) The Effective Educator. December 2010/January 2011 | Volume 68 | Number 4 Pages 35-39

Duke, Daniel L \& Stiggins, Richards J. (1986). Teacher evaluation: Five Keys to Growth. The National Education Association, Washington, D.C.

Evertson, C., \& Weinstein, C. S. (Eds.). (2006). Handbook of classroom management: Research, practice, and contemporary issues. Mahwah, $\mathrm{NJ}$ : Erlbaum.

Flippo, B.E (1980) Personne/Management: Modern Concept, Tokyo McGraw-Hill Co

Good, T. L., \& Brophy, J. E. (2003). Looking in classrooms (9th ed). Boston: Allyn and Bacon. Janes, S (N.A). Effective Evaluation of Teachers. http//www.ehow.com.

Marzano, R. J. (2007). The art and science of teaching: A comprehensive framework for effective instruction. Alexandria, VA: ASCD.

Marzano, R. J., Frontier, T., \& Livingston, D. (2011). Effective supervision: Supporting the art and science of teaching. Alexandria, VA: ASCD.

Marzano. R.J. (2012). www.ascd.org//publication/educationEl Educationl eadershih/vol. 70/ No.3 Nnabuo, P.O.M (1990) Supervision and Inspection: A humanistic approach. Port Harcourt, Bengray publishing company

Ogusaju S (1978) (eds) Secondary Education in Nigeria; Ile Ife: University of I fe Press

Okeke B.S. (2004) Teaching in Nigeria; the Bureaucracy and Professionalism. Port Harcourt: Mercury International Publishing Nigeria.

Sheets, R. H., \& Gay, G. (1996, May). Student perceptions of disciplinary conflict in ethnically diverse classrooms. NASSP Bulletin, 80(580), 84-93.

Strong, M. (2011). The highly qualified teacher: What is teacher quality and how do you measure it? New York: Teachers College Press.

Wang, M. C., Haertel, G. D., \& Walberg, H. J. (1993). Toward a knowledge base for school learning. Review of Educational Research, 63(3), 249-294.

\section{Appendix 1}

Figure 1 contains 41 classroom strategies and teacher behavior all of which have research supporting their relationship with student achievement.

Figure 1. A model of classroom strategy and behavior

1. Routine Strategies

A. Communicating Learning Goals, Tracking Student Progress, and Celebrating Success

1. Providing clear learning goals and scales to measure these goals

2. Tracking student progress 


\section{Celebrating student success}

B. Establishing and Maintaining Classroom Rules and Procedures

4. Establishing classroom rules and procedures

5. Organizing the physical layout of the classroom

2. Content Strategies

C. Helping Students Interact with New Knowledge

\section{Identifying critical information}

7. Organizing students to interact with new knowledge

8. Previewing new content

9. Chunking content into "digestible bites"

10. Processing new information

11. Elaborating on new information

12. Recording and representing knowledge

13. Reflecting on learning

D. Helping Students Practice and Deepen Their Understanding of New Knowledge

\section{Reviewing content}

15. Organizing students to practice and deepen knowledge

16. Using homework

17. Examining similarities and differences

18. Examining errors in reasoning

19. Practicing skills, strategies, and processes

20. Revising knowledge

E. Helping Students Generate and Test Hypotheses about New Knowledge

21. Organizing students for cognitively complex tasks

22. Engaging students in cognitively complex tasks involving hypothesis generation and testing

23. Providing resources and guidance

3. Strategies Enacted on the Spot

F. Engaging Students

24. Noticing when students are not engaged

25. Using academic games

26. Managing response rates

27. Using physical movement

28. Maintaining a lively pace

29. Demonstrating intensity and enthusiasm

30. Using friendly controversy

31. Providing opportunities for students to talk about themselves

32. Presenting unusual or intriguing information

G. Recognizing and Acknowledging Adherence or Lack of Adherence to Rules and Procedures

33. Demonstrating "withitness"

34. Applying consequences for lack of adherence to rules and procedures

35. Acknowledging adherence to rules and procedures

$\mathrm{H}$. Establishing and Maintaining Effective Relationships with Students

36. Understanding students' interests and backgrounds

37. Using verbal and nonverbal behaviors that indicate affection for students

38. Displaying objectivity and control

H. Communicating High Expectations for All Students

39. Demonstrating value and respect for low-expectancy students

40. Asking questions of low-expectancy students

41. Probing incorrect answers with low-expectancy students

Items in bold text may be used to rapidly rate teacher competence in the classroom-that is, as a measurement tool as opposed to a development tool. 